J. Clin. Chem. Clin. Biochem.

Vol. 28, 1990, pp. 605-609

(C) 1990 Walter de Gruyter \& Co.

Berlin · New York

\title{
An Improved Method for Quantitative Determination of Urinary Porphyrins by Use of Second-Derivative Spectroscopy
}

\author{
By A. W. van de Giessen and E. M. van Wijk \\ Clinical Chemistry Department, Military Hospital "Dr. A. Mathijsen", Utrecht, The Netherlands
}

(Received September 13, 1989/June 11, 1990)

Summary: An improved assay for quantification of urinary porphyrins by use of second-derivative spectroscopy is described. A new method for calculation of the porphyrin concentration is developed and the whole procedure is computerized. Acidified urine samples can be assayed within a few minutes by using this method. Precision and recoveries for both uro- and coproporphyrin are good. The method is presented as a very fast and accurate assay for the screening and quantification of urinary porphyrins.

\section{Introduction}

Disorders of the haem biosynthetic pathway can give rise to a group of diseases known as the porphyrias. Diagnosis rests on the combination of a typical clinical picture and the detection of excess amounts of excreted porphyrins or their precursors (1). Quantification of urinary porphyrins is possible by using several chromatographic methods $(2-7)$. However, as porphyria is a very rare disease, the main goal when determining urinary porphyrins is to exclude porphyria as the cause of an unexplained illness. For this purpose rapid screening-tests were developed by Schmitt (8) and Jones \& Sweeney (9), by using secondderivative spectroscopy, and recently more accurate spectrofluorometric methods $(10,11)$ have come into use. In our study we have improved the spectrophotometric method of Jones \& Sweeney (9) to achieve a rapid and accurate method for quantitative determination of total porphyrins in urine and estimation of the molar fractions of uroporphyrin and coproporphyrin.

\section{Materials and Methods}

Uroporphyrin I and coproporphyrin III methyl esters were purchased from Sigma Chemical Co., UK. After hydrolysis of the esters in $\mathrm{HCl}(6 \mathrm{~mol} / \mathrm{l})$ for 5 days, standard solutions of uroporphyrin and coproporphyrin were prepared in $1 \mathrm{~mol} / \mathrm{l}$ $\mathrm{HCl}$ and the concentrations were established spectrophotometrically by use of the extinction coefficients of Falk (12).
Absorbance spectra between 245 and $375 \mathrm{~nm}$ were recorded versus water as the optical reference, using a $2000 \mathrm{UV} / \mathrm{VIS}$ spectrophotometer (Bausch and Lomb Analytical Systems Div., Rochester, NY, USA). The instrument was equipped with a flowcell and had a slit-width of $2 \mathrm{~nm}$. The absorbance data (A) were transmitted through a RS-232 interface to a HP-85 microcomputer (Hewlett Packard Co., Corvallis, OR, USA). The computer generated absorbance data at $0.4 \mathrm{~nm}$ intervals, using a scanspeed of $50 \mathrm{~nm} / \mathrm{min}$. At this setting both the accuracy and the speed of the scan were satisfactory. A computer program was written to generate first- and second-derivatives $\left(\mathrm{dA} / \mathrm{d} \lambda\right.$ and $\left.\mathrm{d}^{2} \mathrm{~A} / \mathrm{d} \lambda^{2}\right)$ in respect to wavelength $(\lambda)$. Derivatives were computed as differences between absorbances. As the accuracy of this method is very much dependent on the value of $\Delta \lambda$ used to calculate the derivatives, experiments were done to find the optimal value.

Test mixtures of standard solutions were prepared of various concentrations of total porphyrins and of various proportions of uroporphyrin and coproporphyrin. According to Jones \& Sweeney (9), both the magnitude of the second-derivative deflection and the wavelength at which the minimum occurs are dependent on the proportions of uroporphyrin and coproporphyrin in the solution. By extensively measuring our test mixtures, the uroporphyrin/coproporphyrin ratio was established as a function of the wavelength of the second-derivative minimum. Instead of the size of the deflection we used the area under the $\mathrm{x}$-axis above the second-derivative curve as a measure for the total porphyrin concentration. The area was calculated for each ratio of uro- and coproporphyrin at a total concentration of $1 \mu \mathrm{mol}$. This 'second-derivative absorptivity' was established as a function of the uroporphyrin/coproporphyrin ratio.

Urine specimens were prepared by diluting $1.0 \mathrm{ml}$ aliquots of centrifuged urine $\left(2000 \mathrm{~min}^{-1}, 5 \mathrm{~min}\right)$ with $4.0 \mathrm{ml}$ of $\mathrm{HCl}(1.25$ $\mathrm{mol} / \mathrm{l})$ containing the sodium salt of EDTA $(1.0 \mathrm{mmol} / \mathrm{l})$. To convert porphyrinogens into porphyrins, $50 \mu \mathrm{l}$ of hydrogen 
peroxide solution $(270 \mathrm{~g} / \mathrm{l})$ were added. After determining the wavelength of the second-derivative minimum and measuring the area under the $\mathrm{x}$-axis, the uroporphyrin/coproporphyrin ratio and the 'second-derivative absorptivity' were known and porphyrin concentrations could be calculated. All calculations were added to the computer program so that it would finally give figures for total porphyrin concentration, uro- and coproporphyrin molar fractions and uro- and coproporphyrin concentrations.

Analytical recovery, precision and interference studies were carried out by accepted protocols (13). The analytical range of our method was determined. To verify recent critical reports (10) on the oxidation procedure used here we compared the effectiveness of oxidation by $\mathrm{H}_{2} \mathrm{O}_{2}$ and iodine at various concentrations. We compared results from our method with those of Horchner \& Rietveld (14) using high performance liquid chromatography (HPLC) and with those of Doss (15) using ion-exchange chromatography. All urine specimens were preserved by the method recommended by Fernandez-Cano \& Labbe (16).

\section{Results}

The first- and second-derivative spectra were very much influenced by the value of $\Delta \lambda$ used (fig. 1). When assaying a urine sample of low porphyrin concentration the use of low values for $\Delta \lambda$ caused much disturbance in the first- and second-derivative spectra. On the other hand, the use of high values for $\Delta \lambda$ gave rise to a shift in the first-derivative spectrum when assaying urine samples with a rapidly rising background absorbance. In many of those cases the second-derivative minimum failed to correspond to the absorbance maximum, leading to incorrect estimations of the uro- and coproporphyrin fractions. We found a value of $8.0 \mathrm{~nm}$ to be the optimal $\Delta \lambda$ for use in our assay.

Table 1 shows the wavelength of the second-derivative minimum $(\lambda$-min) and the 'second-derivative absorptivity' at different porphyrin compositions. As our computer generates absorbance data at $0.4 \mathrm{~nm}$ intervals, the given values for $\lambda$-min are not mean values, but the measurement points closest to the mean values

Tab. 1. Wavelength of the second-derivative minimum and 'second-derivative absorptivity' for different porphyrin compositions.

\begin{tabular}{llllr}
\hline $\begin{array}{l}\text { Uro- } \\
\text { porphyrin } \\
\%\end{array}$ & $\begin{array}{l}\text { Copro- } \\
\text { porphyrin } \\
\%\end{array}$ & $\lambda-\min$ & $\begin{array}{l}\mathrm{d}^{2} \mathrm{~A} / \mathrm{d}^{2} / \\
\mu \mathrm{mol}^{*} \\
\text { mean }(\mathrm{n}=6)\end{array}$ & $\mathrm{SD}$ \\
\hline 0 & 100 & 403.1 & 4431 & 73.0 \\
10 & 90 & 403.5 & 4280 & 137.8 \\
20 & 80 & 403.9 & 4181 & 81.8 \\
30 & 70 & 404.3 & 4132 & 121.2 \\
40 & 60 & 404.7 & 4134 & 118.6 \\
50 & 50 & 405.1 & 4186 & 91.7 \\
60 & 40 & 405.5 & 4290 & 46.4 \\
70 & 30 & 405.9 & 4444 & 79.0 \\
80 & 20 & 406.3 & 4649 & 92.7 \\
90 & 10 & 406.7 & 4905 & 57.0 \\
100 & 0 & 407.1 & 5212 & 167.1 \\
\hline
\end{tabular}

* The magnitude of those values is proportional to porphyrin concentration but in absolute terms depends upon the operating conditions of the computer.
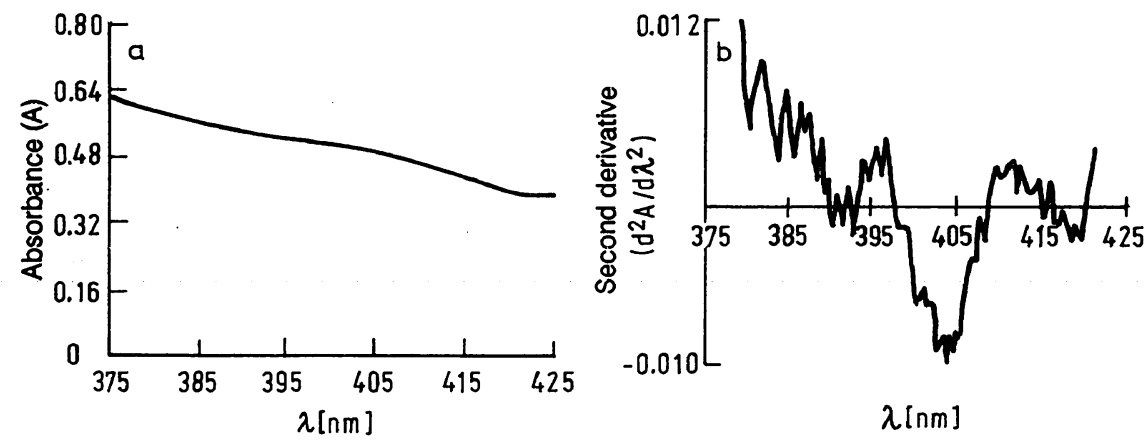

$\lambda[\mathrm{nm}]$

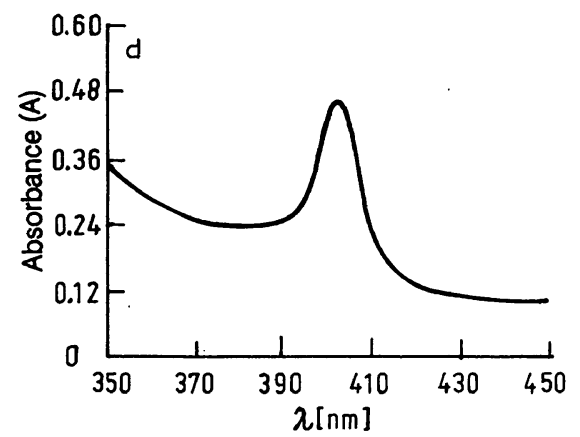

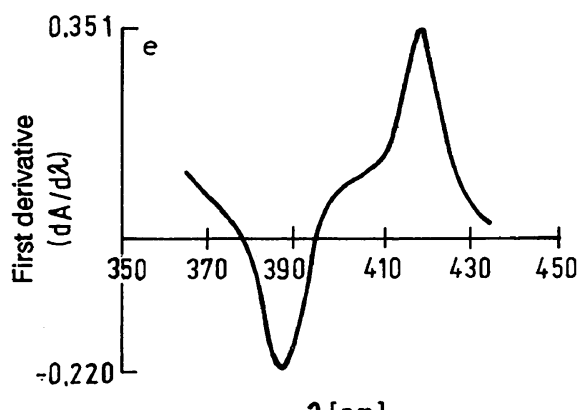

$\lambda[\mathrm{nm}]$
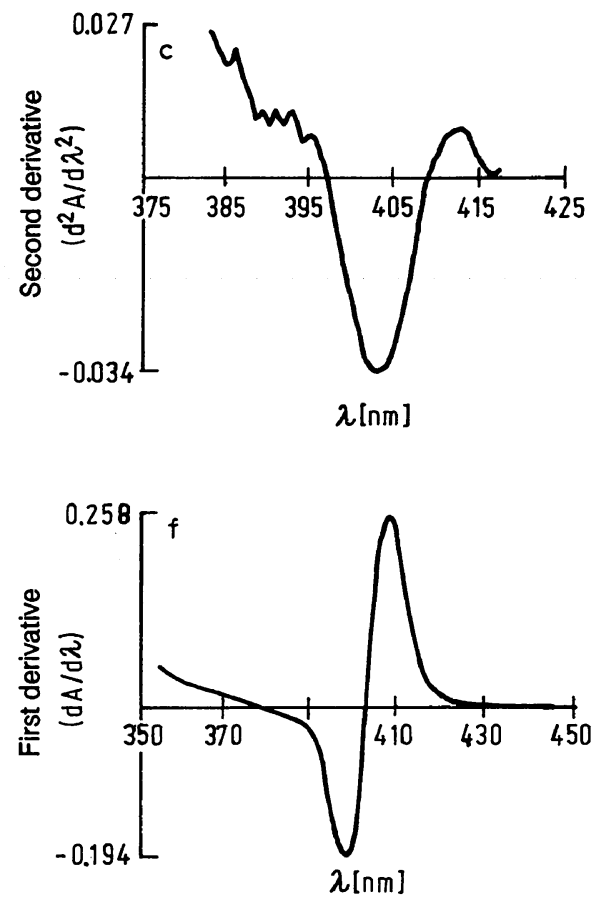

Fig. 1. Absorption spectrum (a) of a urine sample with low porphyrin concentration; second-derivative spectra generated by using a $\Delta \lambda$ of $4.0 \mathrm{~nm}$ (b) and $8.0 \mathrm{~nm}$ (c); absorption spectrum (d) of a urine sample with a high porphyrin concentration, and its first-derivative spectra (e, $f$ ) generated by using a $\Delta \lambda$ of $16.0 \mathrm{~nm}$ (e) and $8.0 \mathrm{~nm}(\mathrm{f})$. 


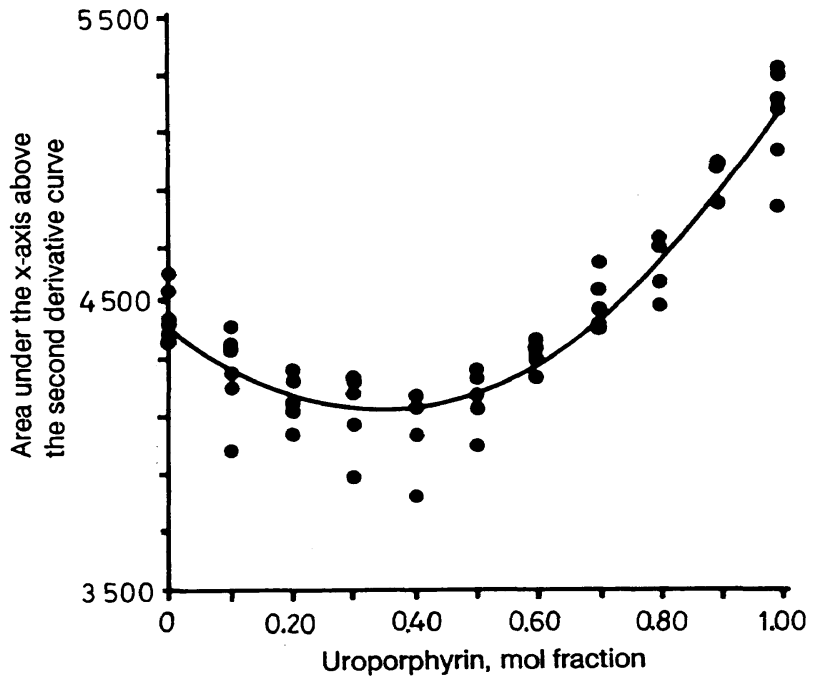

Fig. 2. The relationship between the area under the $x$-axis above the curve of the second-derivative spectrum of porphyrin solutions at a concentration of $1 \mu \mathrm{mol} / 1$ and the uroporphyrin molar fraction in these solutions $(\bullet)$. The 'second-derivative absorptivity' $(y)$ is shown as a second-grade function $\left(y=2539 x^{2}-1759 x+4430\right)$ of the uroporphyrin molar fraction (x).

for $\lambda$-min. There was a difference of $4.0 \mathrm{~nm}$ between the second-derivative minima of pure uroporphyrin and pure coproporphyrin solutions. Lowest 'secondderivative absorptivities' were found for mixtures containing 30 to 40 percent of uroporphyrin, which is in agreement with the results of Christensen et al. (19). The 'absorptivities' found by Jones \& Sweeney (9) are rough values and therefore less useful for comparison. The 'second-derivative absorptivities' presented in our study are not physical constants, because the magnitude of their absolute values is dependent on instrumental settings. Figure 2 shows the 'second-derivative absorptivity' (y) as a second-grade function $\left(y=2539 x^{2}-1759 x+4430\right)$ of the uroporphyrin molar fraction (x).

Table 2 shows analytical recovery data. Different amounts of uro- and coproporphyrin were added to urine samples of various porphyrin concentrations. Individual recoveries ranged from $93 \%$ to $101 \%$ and were averaged to give $97 \%$ recovery for uroporphyrin and $98 \%$ recovery for coproporphyrin, which corresponds to $2 \%$ to $3 \%$ proportional errors or actual errors of 2 to $3 \mathrm{nmol} / 1$ at a total concentration of 100 $\mathrm{nmol} / \mathrm{l}$.

Table 3 shows the results of the precision study. Urine samples containing various concentrations of porphyrins were used in the study. Within-day and between-day precisions were established. For the quantitative results the $\mathrm{CV}$ was $3.5 \%$ or less at all concentrations except for one. Estimation of the uro- and
Tab. 2. Analytical recovery of uro- and coproporphyrin.

\begin{tabular}{|c|c|c|c|c|c|}
\hline \multirow{2}{*}{$\begin{array}{l}\text { Urine } \\
\text { sample } \\
\text { No. }\end{array}$} & \multicolumn{2}{|l|}{ Added } & \multirow{2}{*}{$\begin{array}{l}\text { Measured } \\
(\mathrm{nmol} / \mathrm{l})\end{array}$} & \multirow{2}{*}{$\begin{array}{l}\text { Recovered } \\
(\mathrm{nmol} / \mathrm{l})\end{array}$} & \multirow{2}{*}{$\begin{array}{l}\text { Recov- } \\
\text { ery } \\
\%\end{array}$} \\
\hline & $(\mu \mathrm{l} / \mathrm{ml})$ & $(\mathrm{nmol} / \mathrm{l})$ & & & \\
\hline \multicolumn{6}{|c|}{ Uroporphyrin ( $\mathrm{n}=4$ each) } \\
\hline 1 & 0 & 0 & 71 & - & - \\
\hline 1 & 50 & 307 & 382 & 311 & 101 \\
\hline 1 & 100 & 614 & 660 & 589 & 96 \\
\hline 2 & 0 & 0 & 173 & - & - \\
\hline 2 & 50 & 300 & 451 & 278 & 93 \\
\hline 2 & 100 & 600 & 763 & 590 & 98 \\
\hline 3 & 0 & 0 & 463 & - & - \\
\hline 3 & 50 & 296 & 748 & 285 & 96 \\
\hline 3 & 100 & 592 & 1023 & 560 & 95 \\
\hline \multicolumn{6}{|c|}{ Coproporphyrin ( $\mathrm{n}=4$ each) } \\
\hline 4 & 0 & 0 & 72 & - & - \\
\hline 4 & 50 & 253 & 323 & 251 & 99 \\
\hline 4 & 100 & 507 & 569 & 497 & 98 \\
\hline 5 & 0 & 0 & 213 & - & - \\
\hline 5 & 50 & 290 & 487 & 274 & 94 \\
\hline 5 & 100 & 580 & 795 & 582 & 100 \\
\hline 6 & 0 & 0 & 412 & - & - \\
\hline 6 & 50 & 278 & 677 & 265 & 95 \\
\hline 6 & 100 & 555 & 962 & 550 & 99 \\
\hline
\end{tabular}

Tab. 3. Precision of the method.

\begin{tabular}{|c|c|c|c|c|c|}
\hline \multicolumn{3}{|c|}{ Total porphyrins } & \multicolumn{3}{|c|}{ Molar fraction } \\
\hline $\begin{array}{l}\text { Mean } \\
(\mathrm{nmol} / \mathrm{l})\end{array}$ & $\mathrm{SD}$ & $\begin{array}{l}C V \\
(\%)\end{array}$ & $\begin{array}{l}\text { Uro- } \\
\text { porphyrin }\end{array}$ & $\begin{array}{l}\text { Copro- } \\
\text { porphyrin }\end{array}$ & (SD) \\
\hline \multicolumn{6}{|c|}{ Within-run $(\mathrm{n}=10)$} \\
\hline 61.9 & 1.8 & 2.9 & 0.00 & 1.00 & $(0.00)$ \\
\hline 139.3 & 2.9 & 2.0 & 0.27 & 0.73 & $(0.10)$ \\
\hline 300.3 & 10.7 & 3.5 & 0.08 & 0.92 & $(0.08)$ \\
\hline 1003.0 & 25.2 & 2.5 & 0.73 & 0.27 & $(0.06)$ \\
\hline 8698.4 & 58.4 & 0.6 & 0.90 & 0.10 & $(0.00)$ \\
\hline \multicolumn{6}{|c|}{ Between-run $(n=10)$} \\
\hline 61.6 & 1.9 & 3.0 & 0.05 & 0.95 & $(0.08)$ \\
\hline 127.5 & 4.1 & 3.2 & 0.14 & 0.86 & $(0.09)$ \\
\hline 311.3 & 22.4 & 7.2 & 0.11 & 0.89 & $(0.09)$ \\
\hline 991.7 & 21.8 & 2.2 & 0.72 & 0.28 & $(0.04)$ \\
\hline 8162.9 & 48.5 & 0.6 & 1.00 & 0.00 & $(0.00)$ \\
\hline
\end{tabular}

coproporphyrin fractions revealed a maximal standard deviation of 0.10 each; thus, concentrations of uroporphyrin and coproporphyrin can be calculated accurately enough for clinical interpretation.

A linear relationship between the second-derivative area under the $\mathrm{x}$-axis and the quantity of porphyrins was shown by using dilutions of urine specimens containing high concentrations of porphyrins. The relationship was linear to at least $10000 \mathrm{nmol} / \mathrm{l}$. As it is impossible to obtain results for a blank by using a second-derivative method, we established an arbitrary detection limit of $20 \mathrm{nmol} / \mathrm{l}$. Repeated assay of urine specimens with concentrations near to $20 \mathrm{nmol} / 1$ yielded coefficients of variation of $5 \%$. 
Haemoglobin at $100 \mathrm{mg} / \mathrm{l}$ and bilirubin at $100 \mu \mathrm{mol} / \mathrm{l}$ did not distort the shape of the derivative spectra, and therefore had no influence on the accuracy of the determination.

Contrary to the results of Westerlund et al. (10) we found no significant difference in the efficacy of oxidation by hydrogen peroxide or iodine (Mann-Whitney-U-test; $\mathrm{p}>0.1$ ). Porphyrin concentrations of acidified urine samples were equally enhanced by addition of $\mathrm{H}_{2} \mathrm{O}_{2}$ or iodine.

Table 4 gives the results of the comparison study. The results obtained by our method correlated well with those from the HPLC-method $(14)\left(r^{2}=0.99\right)$ and from the ion-exchange method of Doss (15) $\left(r^{2}=0.99\right)$.

Tab. 4. Comparison of results of porphyrin measurement by second-derivative spectrophotometry (y) in both normal and pathological urine samples with those from high performance liquid chromatography (HPLC) $\left(x_{1}\right)$ and those from ion-exchange chromatography $\left(x_{2}\right)$.

\begin{tabular}{|c|c|c|c|}
\hline \multirow{3}{*}{$\begin{array}{l}\text { Urine } \\
\text { sample } \\
\text { No. }\end{array}$} & \multicolumn{3}{|c|}{ Total porphyrin concentration, nmol/l } \\
\hline & Spectro- & HPLC & Ion- \\
\hline & (y) & $\left(\mathrm{x}_{1}\right)$ & $\left(\mathrm{x}_{2}\right)$ \\
\hline 1 & $<20$ & - & $<20$ \\
\hline 2 & $<20$ & 90 & $<20$ \\
\hline 3 & $<20$ & 41 & $<20$ \\
\hline 4 & 32 & 78 & $<20$ \\
\hline 5 & 52 & 85 & 61 \\
\hline 6 & 65 & 100 & 43 \\
\hline 7 & 66 & - & 100 \\
\hline 8 & 69 & - & 155 \\
\hline 9 & 74 & 78 & 61 \\
\hline 10 & 100 & 154 & 117 \\
\hline 11 & 104 & 380 & 61 \\
\hline 12 & 123 & - & 203 \\
\hline 13 & 148 & 184 & 185 \\
\hline 14 & 194 & 218 & 227 \\
\hline 15 & 296 & 238 & 320 \\
\hline 16 & 462 & 494 & 517 \\
\hline 17 & 507 & 484 & 360 \\
\hline 18 & 879 & 980 & 802 \\
\hline 19 & 958 & 913 & 668 \\
\hline 20 & 2405 & 2291 & 1289 \\
\hline 21 & 3298 & 2786 & 2270 \\
\hline 22 & 16162 & 12265 & 10883 \\
\hline
\end{tabular}

Regression lines: $\mathrm{y}=1.32 \mathrm{x}_{1}-172$

$\mathrm{y}=1.49 \mathrm{x}_{2}-59$

\section{Discussion}

Clinical features of porphyria are variable and often vague. Diagnosis depends heavily on chemical analysis of excretion products. For that reason a lot of urine samples enter clinical laboratories to be assayed for porphyrins. As urine from someone with porphyria contains much higher amounts of porphyrins than normal urine, it is quite easy to distinguish positive cases from negative cases. For urine porphyrin measurement many laboratories still use methods involving chromatographic separations. These procedures are time-consuming and therefore not useful for fast screening of urine samples, in contrast to the spectrophotometric measurement of porphyrins, which is very fast and easy. In recent studies (17) a fairly simple screening-test involving spectrophotometric scanning showed excellent performance.

By using second-derivative spectrophotometry and computerization our method is faster and more accurate than any other screening-test for porphyrins published so far. Using our computerized method, results for a urine specimen can be obtained within 5 minutes. The precision of the method has improved considerably, compared with the results obtained by Jones \& Sweeney (9), especially for low porphyrin concentrations. The area under the $\mathrm{x}$-axis above the second-derivative curve proves to be a more reliable measure of porphyrin concentration than the secondderivative deflection used by Jones \& Sweeney (9). Whereas the influence of porphyrin composition on the second-derivative output is neglected by some authors (18), this factor is integrated in our computer program and enhances the accuracy of the method. Precision and recoveries of uro- and coproporphyrin were at least as good as those by the spectrofluorometric method of Westerlund et al. (10). Some authors $(9,10)$ do not mention the porphyrin concentration and composition of the urine samples used for the recovery study, although those figures are important when considering the results of the study.

Estimation of the uro- and coproporphyrin fractions by the second-derivative minimum is still not perfect, as an error of $0.4 \mathrm{~nm}$ (the step used in our spectra) in determining the second-derivative minimum can easily occur. However, the results of the precision study show that errors greater than 0.10 in uro- and coproporphyrin fractions will occur only infrequently. Thus, the estimations of the uro- and coproporphyrin fractions are considered to be an indication of the porphyrin composition, and they help to differentiate coproporphyria from types of porphyria in which uroporphyrin predominates.

The results of the comparison study are satisfactory. However, at low porphyrin levels, the differences between the results are relatively large, especially for urine no. 11. We attribute this to the large CV-values $(10-20 \%)$ of the chromatographic assays and the inaccurate methods for calculation of the porphyrin concentration used in those assays, which are clearly 
critical at low porphyrin levels. At high porphyrin levels, values obtained by the chromatographic methods are lower, which might be due to incomplete extraction.

Chromatographic methods will certainly retain their value for differential diagnosis of porphyrias; differentiation into uro- and coproporphyrin by spectrophotometric methods becomes impossible especially when intermediate forms of porphyrin are present in an urine sample $(19,20)$. In other cases, such as acute porphyria during remission, and erythropoietic protoporphyria, the level of urinary porphyrin is normal. However, spectrophotometric methods for detection of elevated urinary porphyrin levels are valuable for screening purposes.

\section{References}

1. Hindmarsh, J. T. (1986) The porphyrias: recent advances. Clin. Chem. 32, 1255-1263.

2. Martinez, C. A. \& Mills, G. C. (1971) Spectrophotofluorometric determination of porphyrins in urine. Clin. Chem. 17, 199-205.

3. Sobel, C., Cano, C. \& Thiers, R. E. (1974) Separation and quantitation of coproporphyrin and uroporphyrin in urine. Clin. Chem. 20, 1397-1402.

4. Gray, C. H., Lim, C. K. \& Nicholson, D. C. (1977) The differentiation of the porphyrias by means of high pressure liquid chromatography. Clin. Chim. Acta 77, 167-178.

5. Ford, R. E., Ou, C. N. \& Ellefson, R. D. (1981) Liquidchromatographic analysis for urinary porphyrins. Clin. Chem. 27, 397-401.

6. Schreiber, W. E., Raisys, V. A. \& Labbe, R. F. (1983) Liquid-chromatographic profiles of urinary porphyrins. Clin. Chem. 29, 527-530.

7. Lim, C. K. \& Peters, T. J. (1984) Urine and faecal porphyrin profiles by reversed-phase high-performance liquid chromatography in the porphyrias. Clin. Chim. Acta 139, $55-63$.

8. Schmitt, A. (1977) Bestimmung der Gesamtporphyrine in Urin durch Derivativ-Spektroskopie. J. Clin. Chem. Clin. Biochem. 15, 303-306.

9. Jones, K. G. \& Sweeney, G. D. (1979) Quantitation of urinary porphyrins by use of second-derivative spectroscopy. Clin. Chem. 25, 71-74.

10. Westerlund, J., Pudek, M. \& Schreiber, W. E. (1988) A rapid and accurate spectrofluorometric method for quantification and screening of urinary porphyrins. Clin. Chem. $34,345-351$

11. Polo, C. F., Frisardi, A. L., Resnik, E. R., Schoua, A. E. M. \& Batlle, A. M. del C. (1988) Factors influencing fluorescence spectra of free porphyrins. Clin. Chem. 34, 757760.
Although some screening tests for porphyria have proved their capacity to differentiate positive cases efficiently from negative cases, we think it is preferable to use a test that combines efficiency with accuracy. Our method combines the ease of a rapid screening procedure with accurate determination of the total urinary porphyrin concentration. Every laboratory supplied with a spectrophotometer and an attached microcomputer, can easily adapt this method and benefit from its great clinical usefulness.

\section{Acknowledgement}

We thank Dr. J. W. O. van den Berg (Laboratory Internal Medicine 2, Academic Hospital Rotterdam) for providing the pathological urine samples and Mrs. I. I. den Hollander for correcting the manuscript.

12. Falk, J. E. (1964) Porphyrins and metalloporphyrins, 2nd edn., pp. 232-253, Elsevier Publ. Co., Amsterdam.

13. Peters, T. \& Westgard, J. O. (1986) Evaluation of methods. In: Textbook of clinical chemistry, 3rd edn. (Tietz, N. W., ed.) pp. 410-423, W. B. Saunders, Philadelphia.

14. Horchner, P. \& Rietveld, T. (1976) Rapid method for the quantitative determination of porphyrin methyl esters by high pressure liquid chromatography. J. Chromatogr. 123, 414-418.

15. Doss, M. O. (1974) Porphyrins and porphyrin precursors. In: Clinical Biochemistry, principles and methods, 2nd edn. (Curtius, H. C. \& Roth, M., eds.) pp. 1322-1371, W. de Gruyter, New York.

16. Fernandez-Cano, P. \& Labbe, R. F. (1983) Specimen collection for urinary porphyrin studies. Clin. Chim. Acta 132, $317-320$.

17. Deacon, A. C. (1988) Performance of screening tests for porphyria. Ann. Clin. Biochem. 25, 392-397.

18. Walters, M. \& Thornton, D. J. (1986) Multiwavelength analyses of derivative spectra: an application for the determination of urinary porphyrins. Clin. Chim. Acta 157, $311-316$.

19. Christensen, N. G., Johannessen, B. \& Romslo, I. (1977) A rapid assay of urinary porphyrins by dual-wavelength spectrophotometry. Clin. Chim. Acta 81, 229-235.

20. Ficheaux, H., Levillain, P. \& Lemonnier, A. (1989) Dosage spectrophotometrique direct de l'uroporphyrine et de la coproporphyrine urinaires par la methode du point d'annulation en derivée seconde. Ann. Biol. Clin. 47, 196-201.

Dr. E. M. van Wijk

Clinical Chemistry Dept.

Medisch Centrum De Klokkenberg

Postbus 90108

NL-4800 RA Breda 
